INVITED REVIEW

\title{
Emergency Laparotomies: Causes, Pathophysiology, and Outcomes
}

\author{
Armin Ahmed ${ }^{1}$, Afzal Azim ${ }^{2}$
}

\begin{abstract}
Emergency laparotomies have remained a challenging entity since many decades. Only during the past 10 years, serious efforts have been made to improve their outcome by conducting audits and designing care pathways. Indications for emergency laparotomies can be broadly classified into trauma and non-trauma surgeries, which are either done for control of hemorrhage or/and done for control of sepsis and organ dysfunction. Goal-directed resuscitation for septic/hemorrhagic shock, consultant-led multidisciplinary teams, and timely transfer to intensive care units form core principles of management for these patients. Global inequity in access to standard and affordable emergency surgeries is an area of concern requiring integrated efforts at international level.
\end{abstract}

Keywords: Emergency laparotomy, Perioperative care, Perioperative mortality, Quality improvement.

Indian Journal of Critical Care Medicine (2020): 10.5005/jp-journals-10071-23612

\section{INTRODUCTION}

Emergency laparotomies form a broad group of time-sensitive surgeries done on variable patient population. Broadly, they can be divided into trauma and non-trauma laparotomies. Most common non-trauma surgeries include laparotomies done for intestinal perforation and obstruction, while trauma laparotomies are done for hemorrhage control as well as control of peritoneal spillage after bowel injury. Average mortality rate after emergency laparotomies range from $10 \%$ to $18 \%$ in different studies which is much higher than elective surgeries. ${ }^{1}$ There is significant global inequity among different countries in terms of access to standard emergency surgical facilities, with lower income countries sharing the highest burden of surgical mortalities.

Regular audits and perioperative care pathways have been used to enhance outcome of these surgeries in many highincome countries. ${ }^{2}$ As these countries already have separate welldeveloped trauma care network, only non-trauma laparotomies (acute abdomen) are included in their audits and care pathways for emergency laparotomies. National Emergency Laparotomy Audit (NELA), Australian and New Zealand Emergency Laparotomy Audit-Quality Improvement (ANZELA-QI), and American College of Surgeons National Surgical Quality Improvement Program (ACSNSQIP) are some of the large national-level audit programs for improving care in this subgroup of surgical patients. NELA, a joint national audit, was started in 2012 in response to high mortality seen in emergency laparotomy in Great Britain and Ireland. NELA gave standards of care that were subject to RAG rating (i.e., red $=$ not met, amber = partially met, and green = met). The 30-day mortality among emergency laparotomy patients reduced from $11 \%$ in first report in 2015 to $9.6 \%$ in fifth report in $2019 .^{3}$ Note that NELA includes only surgeries done on gastrointestinal tracts and excludes all appendicectomies, cholecystectomies as well as trauma, vascular, obstetric, and transplant laparotomies.

Elective surgery patient care pathways like enhanced recovery after surgery (ERAS) has caused significant reduction in morbidity and length of stay for elective surgery patients, but such welldefined evidence-based pathways are still evolving in the field of emergency laparotomy. Extending the components of elective
'Department of Critical Care Medicine, King George Medical University, Lucknow, Uttar Pradesh, India

${ }^{2}$ Department of Critical Care Medicine, Sanjay Gandhi Postgraduate Institute of Medical Sciences, Lucknow, Uttar Pradesh, India

Corresponding Author: Afzal Azim, Department of Critical Care Medicine, Sanjay Gandhi Postgraduate Institute of Medical Sciences, Lucknow, Uttar Pradesh, India, Phone: +91 8004904730, e-mail: afzalazim38@gmail.com

How to cite this article: Ahmed A, Azim A. Emergency Laparotomies: Causes, Pathophysiology, and Outcomes. Indian J Crit Care Med 2020;24(Suppl 4):S183-S189.

Source of support: Nil

Conflict of interest: None

surgery pathways to emergency laparotomies is difficult because these pathways primarily work by attenuation of stress response to surgery through careful planning and preoperative optimization. Such interventions have limited role in emergency laparotomies, as stress response cascade has already set in by the time patient qualifies for surgery and preoperative optimization is marred by paucity of time. Along with this, emergency laparotomies require appropriately selected fluid, electrolytes, nutrition, and pain management regimen throughout the perioperative period which are more complex and difficult to achieve due to the deranged patient physiology. ${ }^{4}$

\section{Causes}

A wide range of causes form indication for emergency laparotomies. For ease of understanding, the causes can be classified under the following heads:

- Emergency laparotomy in non-trauma patients: Causes for nontrauma emergency laparotomy varies according to geographical areas and patient cohort studied. Among the low- and middleincome countries, appendicectomy is the most common nontrauma laparotomy, while intestinal perforation and obstruction are leading causes in high-income countries. The difference 
reflects delay in seeking treatment for healthcare-related issues and lack of availability of evenly distributed appropriate surgical facilities in low- and middle-income countries.

- Emergency laparotomy in trauma patients: Trauma patients frequently undergo emergency laparotomy for hemodynamic instability and ongoing blood loss. The patient cohort in this subgroup is generally younger and healthier when compared to non-trauma laparotomies. Many of these patients have polytrauma with injuries to chest, pelvis, long bones, etc. A subgroup of these patients may require re-exploration for relapse of bleeding.

- Emergency laparotomy in obstetric patients: Similar to trauma patients, obstetric patients undergoing laparotomy are relatively younger with less or no comorbidities. Most frequently, they are operated for intra-abdominal bleeding following a cesarean section or refractory postpartum hemorrhage. Uterine perforation after septic abortion and uterine rupture after obstructed labor still remain important indications for emergency laparotomies in developing countries. Obstetric patients may also undergo emergency laparotomy for non-obstetric causes among which acute appendicitis and cholecystitis are the most common.

- Emergency laparotomy in malignancy patients: There is limited literature on emergency laparotomies in cancer patients. Intestinal obstruction and perforation are the most common indications. A large number of patients in this subgroup have higher mortality and morbidity due to frailty, poor nutritional status, and compromised immune response.

- Emergency laparotomy in critically ill patients: Critically ill patients may require laparotomy for abdominal compartment syndrome, acute colitis, global or isolated segment ischemia, intestinal perforation following acute pancreatitis, etc. Both operation theater and bedside laparotomy are described in the literature for critically ill patients. Unsurprisingly, bedside laparotomies are associated with very high mortality. ${ }^{5}$

\section{Pathophysiology}

From the pathophysiology point of view, emergency laparotomies fall into two categories, namely, surgeries emergently done for uncontrolled hemorrhage and urgently done for control of sepsis and organ dysfunction. The key physiological derangements in patients requiring emergency laparotomy include hypovolemia, metabolic acidosis, dyselectrolytemia, hypothermia, and coagulopathy.

Peritonitis is seen in a number of emergency laparotomy patients. It is defined as the inflammation of mesothelial lining of abdominal cavity (parietal peritoneum) and visceral organs (visceral peritoneum) and can be classified as primary, secondary, and tertiary. Primary peritonitis that occurs without breach in continuity of the gut is seen in patients with ascites and is mostly monomicrobial in nature. Secondary peritonitis occurs as result of breach in continuity of gastrointestinal tract and spillage of intestinal content into the peritoneal cavity. ${ }^{6}$ If inflammation persists beyond 48 hours after adequate surgical source control, it is labeled as tertiary peritonitis. Both secondary and tertiary peritonitis are polymicrobial and frequently caused by multidrug resistant organisms, including fungi such as Candida albicans and non albicans.

Emergency laparotomy patients are at high risk for abdominal compartment syndrome due to tissue edema, bowel paralysis, ascites, indiscriminate fluid resuscitation, and fluid overload. ACS is defined as raised intra-abdominal pressure leading to new organ dysfunction or failure. Mostly, this is seen with sustained rise in intra-abdominal pressures $>20 \mathrm{~mm} \mathrm{Hg}$ but can also occur at lower pressures. Abdominal cavity can be compared to a box with diaphragm and abdominal wall forming its boundaries. The pressure in the cavity (intra-abdominal pressure IAP) is determined by compliance of the boundaries and abdominal contents. Similar to cerebral perfusion concept, abdominal perfusion pressure is a function of mean arterial pressure minus intra-abdominal pressure $($ APP $=$ MAP-IAP). It can be easily understood that any rise in intraabdominal contents or decreased compliance of the abdominal wall and diaphragm can cause rise in IAP. Rise in abdominal pressure beyond a critical threshold compromises abdominal perfusion leading to ischemic injury to various organs and hemodynamic compromise due to decreased venous return. Khan et al. reported the presence of intra-abdominal hypertension in $80 \%$ patients undergoing emergency laparotomy. ${ }^{7}$

\section{Outcome}

Outcome in emergency laparotomies is governed by patient factors, type of illness, and timely provided appropriate medical and surgical intervention.

\section{Mortality and Risk Factors for Mortality}

Many risk prediction tools have been developed (e.g., P-POSSUM, NELA risk score) to aid risk stratification by clinicians. Table 1 summarizes the commonly used assessment tools used for identifying high-risk emergency laparotomy patients. Complex tools requiring collection of large number of data points are difficult to implement bedside. APACHE II score, although not developed for surgical population, has shown good discrimination constantly in multiple external validation studies done on emergency laparotomy patients.

Barazanchi et al. did a scoping systematic review of 22 studies evaluating risk factors for mortality after emergency laparotomy. ${ }^{3}$ Various risk factors associated with increased mortality after emergency laparotomy were increased age, higher ASA score, functional dependency, comorbidities, preoperative sepsis, and acute physiological derangements (reduced hemoglobin, platelets, albumin, raised TLC, serum creatinine, etc.). Poulton et al. showed link between socioeconomic deprivation and mortality after emergency laparotomy in an observational study involving 58,790 patients. ${ }^{8}$

Recently, frailty has been identified as an independent risk factor for mortality, irrespective of patient's age, but its assessment is frequently missed in preoperative phase. Frailty is defined as increased vulnerability to disease process due to age-associated decline in physiological reserves of multiple organ systems. Frail old-aged patients form a special subgroup of high-risk population with poor outcome. Trotter et al. evaluated sarcopenia as a surrogate marker of frailty in 259 patients undergoing emergency laparotomy. It was measured using psoas density and area on computed tomography (CT) scan. Sarcopenic patients had increased 30-day (29.7\% vs $8.7 \%$; odds ratio $4.42 ; 95 \% \mathrm{Cl} 2.13-9.26 ; p<0.001)$ and 1 -year mortality $(57.8 \%$ vs $18.5 \% ; p<0.001$; odds ratio $6.05 ; 95 \% \mathrm{Cl}$ 3.28-11.18) when compared non-sarcopenic patients. ${ }^{9}$

\section{Complications}

Commonly reported complications include fever, nausea, vomiting, wound infection, sepsis, and secondary infections (pneumonia, 
Emergency Laparotomies: Causes, Pathophysiology, and Outcomes

Table 1: Commonly used scores for prediction of mortality and complications in emergency laparotomies patients

\begin{tabular}{|c|c|c|c|}
\hline S. no. & Score & Calculation & Remarks \\
\hline \multirow[t]{2}{*}{1} & $\mathrm{P}-\mathrm{POSSUM}^{\wedge}$ & $\begin{array}{l}\text { In }[R /(1-R)]=-9.37+(0.19 \times \text { physiological score })+ \\
(0.15 \times \text { operative severity score }) . R \text { is the predicted risk } \\
\text { of mortality. }\end{array}$ & $\begin{array}{l}\text { AUC } * * * \text { for unplanned abdominal surgery } \\
0.65 \text { to } 0.82\end{array}$ \\
\hline & & & $\begin{array}{l}\text { Poor discrimination in patients with colorectal } \\
\text { cancer (AUC } 0.65 \text { to } 0.75 \text { ) }\end{array}$ \\
\hline \multirow[t]{2}{*}{2} & APACHE $\|^{\wedge \wedge}$ & $\begin{array}{l}\text { Physiological variables }+ \text { age points }+ \text { chronic health } \\
\text { points }\end{array}$ & $\begin{array}{l}\text { Not originally developed on } \mathrm{EL}^{* *} \text { population but } \\
\text { shows good discrimination consistently in studies } \\
\text { done on EL patients }\end{array}$ \\
\hline & & & AUC 0.76 to 0.98 \\
\hline \multirow[t]{6}{*}{3} & ASA-PS ${ }^{\wedge \wedge \wedge}$ & ASA I; patient without systemic disease & Poor performance in elderly population (AUC 0.66) \\
\hline & & ASA II; patient with mild systemic disease & AUC 0.73 to 0.91 \\
\hline & & ASA III; patient with severe systemic disease & \\
\hline & & $\begin{array}{l}\text { ASA I; patient with severe life-threatening systemic } \\
\text { disease }\end{array}$ & \\
\hline & & $\begin{array}{l}\text { ASA V; moribund patient who is unlikely to survive to } \\
\text { without surgery }\end{array}$ & \\
\hline & & ASA Vl; brain-dead patient planned for organ donation & \\
\hline \multirow[t]{2}{*}{4} & $\begin{array}{l}\text { NSQIP }{ }^{\wedge \wedge \wedge \wedge} \text { Emergency } \\
\text { laparotomy models. }\end{array}$ & $\begin{array}{l}\text { ACS NSQIP }{ }^{\wedge \wedge \wedge \wedge} \text { dataset used to generate two models } \\
\text { Preoperative and perioperative. }\end{array}$ & $\begin{array}{l}\text { AUC reported as } 0.87-0.88 \text { in internal validation } \\
\text { study }\end{array}$ \\
\hline & & $\begin{array}{l}\text { Uses large number of data points calculated via } \\
\text { electronic platform. Predictions morality as well as } \\
\text { complications of surgery }\end{array}$ & \\
\hline 5 & NELA* risk model & $\begin{array}{l}\text { Two year NELA data ( } 2013 \text { to } 2015 \text { ) was used to } \\
\text { develop the model. Uses multiple data points (includ- } \\
\text { ing age, gender, physiological variables, malignancy, } \\
\text { and ASA status) }\end{array}$ & AUC 0.861 in internal validation study \\
\hline
\end{tabular}

$\wedge$ Portsmouth physiological and operative severity score for the enumeration of mortality; $\wedge \wedge$ Acute physiology and chronic health evaluation; $\wedge \wedge \wedge$ American Society of Anesthesiologists physical scale; $\wedge \wedge \wedge \wedge$ American College of Surgeons National Surgical Quality Improvement Program; *National emergency laparotomy audit risk model; **Emergency laparotomy; ***Area under curve for prediction of 30-day mortality

urinary tract infection). Mortality and complications are very high in old-age patients. A study on emergency laparotomy in patients above 80 years reported 30 -days and 1-year mortality of $26 \%$ and $47 \%$, respectively. Out of 106 patients studied, 51 (48\%) developed pulmonary complications, while 42 (40\%) developed delirium.

\section{Improving Outcome of Patients Undergoing Emergency Laparotomy}

\section{Goal-directed Resuscitation}

The principles of goal-directed resuscitation apply on emergency laparotomy patients similar to any other critically ill patients (Flowchart 1). Fluid optimization in emergency laparotomy (FLOELA) is an ongoing randomized trial to compare cardiac outputguided hemodynamic therapy against usual care in emergency laparotomy patients. ${ }^{2}$ Currently, the trial has been temporarily paused due to COVID-19 pandemic.

Early administration of antibiotics, volume resuscitation with lactate monitoring, vasopressor support to maintain mean arterial pressures $>65 \mathrm{~mm} \mathrm{Hg}$, and timely intubation with institution of lung protective mechanical ventilation are essential components of goal-directed resuscitation.

Direct peritoneal resuscitation (DPR) is the modality of infusing hypertonic solution directly into the peritoneal cavity besides intravenous volume resuscitation. It has been used as an adjunct to damage control surgery, where large-volume resuscitation is needed to manage hemorrhagic and/or septic shock. It acts by causing sustained arteriolar dilatation of intestinal vessels, thus promoting visceral perfusion and reducing organ ischemia along with blunted inflammatory response. Patients managed with DPR have shown reduced bowel edema and higher rates of abdominal closure. Most of the studies available in the literature were conducted at University of Louisville using $2.5 \%$ delflex peritoneal dialysis solution for peritoneal resuscitation. ${ }^{10}$ More data are needed to establish the role of DPR in the management of patients undergoing emergency laparotomy.

\section{Role of Damage Control or Abbreviated Surgery}

Metabolic failure and sepsis that set in during long hours of surgical intervention in patients with deranged physiology were found to be more detrimental than the actual pathology itself. This led to the concept of damage control surgery which initially evolved in trauma patients in early 20th century. Later on, this concept has been extended to certain subgroups of non-trauma emergency laparotomies also (e.g., mesenteric ischemia, complicated diverticulitis). The principles of damage control surgery include initial abbreviated surgery to address life-threatening issues followed by correction of metabolic milieu in intensive care unit and then planned definitive relaparotomy within 24-48 hours. The role of damage control surgery is well established in trauma care, but there is limited literature regarding its use in non-trauma emergency laparotomies. ${ }^{11}$

A meta-analysis and a randomized controlled trial evaluating planned relaparotomy vs need-based relaparotomy in patients undergoing non-trauma emergency laparotomies showed increased number of re-laparotomies and length of stay in planned 
Flowchart 1: Approach to a patient undergoing emergency laparotomy

Sepsis and septic shock management
- Risk stratification (identify the high-
risk group)
- Invasive hemodynamic monitoring
and goal-directed optimization
- Apply principles of surviving sepsis
guidelines
- Early antibiotics and blood cultures

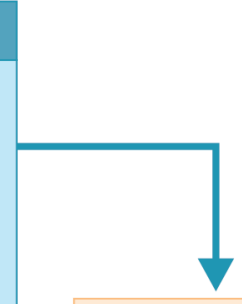

OPERATION THEATER Surgical measures for source control (damage control surgery in patients with deranged metabolic milieu)
Hemorrhage shock management

- Risk stratification

- Invasive hemodynamic

monitoring and optimization

- Blood protocol followed by goal

directed as per point of care

coagulation parameters)

- Apply principles of hemostatic

resuscitation

- Permissive hypotension till

source control achieved re-laparotomy group with no difference in mortality and rates of intra-abdominal abscesses in the two groups. It has been argued that these studies used primary closure and did not utilize the vacuum-assisted closure system and other modern temporary abdominal closure techniques (TAC), which limits its applicability on current practices.

Damage control surgery is associated with a number of complications, of which intra-abdominal infection and enteroatmospheric fistula (EAF) are associated with high morbidity. Similar to any other intervention in medical science, damage control surgery requires appropriate patient selection and surgical skill to be successfully practiced.

\section{Consultant-led Care}

There is growing body of evidence that presence of consultant surgeon and consultant anesthetist in the operation theater for patients undergoing emergency laparotomy has been found to be associated with improved outcome. A retrospective study evaluating the effect of emergency general surgery (EGS) service showed $46.8 \%$ reduction in complications and $53 \%$ reduction in number of deaths from pre-EGS period along with reduction in time spent in emergency (from 8.0 to 6.0 hours; $p$ value $<0.001$ ) and length of hospital stay (from 3.0 to 2.0 days; $p$ value $<0.001$ ). ${ }^{12}$ Presence of consultant is now considered a measure of quality standard of health care. According to NELA (2019) report, consultant surgeon and consultant anesthetist gave inputs before surgery for $95 \%$ and $90 \%$ high-risk patients, respectively, in the United Kingdom. ${ }^{3}$

Further improvement in quality of care can be brought by preoperative input of intensive care specialist and geriatrician in the high-risk old age patients.

Unfortunately, applicability of such principles of care is not always possible in many countries, as $70 \%$ of the world's population still lacks access to basic surgical care.
Postoperative ward/HDU care

- Pain relief

- Physiotherapy and early

mobilization

- Stoma care team

Postoperative ICU care

- Review need for further resuscitation and

hemodynamic optimization

- Extubation after correction of metabolic parameter

- Intra-abdominal pressure monitoring in selected patients

- Non-opioid-based pain control regimen

- Nutrition and physiotherapy

- Early identification and management for complication (atelectasis, pneumonia, delirium)

In order to give momentum to essential emergency healthcare services, many countries are adapting NSOAP (National Surgical, Obstetric and Anesthesia Plan) under the guidance of WHO as an integral target to be achieved by 2030 under the banner of United Nations Sustainable Development Goals. The plan targets to have at least 20 surgical, anesthetic, and obstetric physicians per 100,000 population. ${ }^{13}$

\section{Postoperative Care}

Some guidelines recommend postoperative ICU care for all exploratory patients, while others recommend ICU care for those with expected mortality $>5$ to $10 \%$. Decision to extubate in the postoperative phase should take into consideration hemodynamic stability, correction of metabolic derangements, coexisting pulmonary complications (atelectasis, pneumonia, effusion, etc.), and the ability to handle secretions. Inadequate analgesia is associated with increased pulmonary complications due to poor coughing, myocardial ischemia, and exaggerated stress response.

\section{Stoma Care Team}

Emergency laparotomies often require bowel-related procedures, such as ileostomy or colostomy. Higher rate of stoma-related complications have been reported in emergency laparotomies when compared to elective surgeries ( $48 \%$ vs $25 \%$, respectively), among which skin problems and parastomal hernia were most common. Dedicated stoma care teams have been shown to reduce stoma-related complications and are clearly beneficial.

\section{Patient Selection and No-lap Population}

After the remarkable success of NELA in bringing down mortality in emergency laparotomies from 12 to $10 \%$ in England and Wales, researchers were intrigued to understand the course of illness and natural history of patients who qualified for emergency laparotomy as per the criteria but did not proceed to surgery. Mcllveen et al. 
studied 314 patients who qualified for emergency laparotomy of which 214 (68\%) underwent surgery while 100 (32\%) did not. ${ }^{14}$ Reason for declining surgery was futile care due to poor fitness in $80 \%$ patients, no reason documented in $16 \%$ and patient refusal in $4 \%$ cases. Thirty-day mortality was $24 \%$ in patients who underwent laparotomy, while no-lap patients had $74 \%$ mortality. As more than $25 \%$ patients in the no-lap group survived beyond 30 days, more research is needed to guide surgeons regarding the complex decision of proceeding to surgery or not in high-risk population.

\section{Role of Quality Improvement Programs Using Multidisciplinary Protocol}

As emergency laparotomy patients form a high mortality subgroup of surgical patients, various efforts are being made to bring down the mortality by applying quality improvement programs using multidisciplinary care bundles and protocols. Careful evaluation of mortality studies on emergency patients show multiple delays (e.g., delayed diagnosis, delayed antibiotics, delayed surgery, delayed resuscitation) at the heart of the problem. Therefore, corrective measures include designing bundles based on "timely interventions" and early involvement of "experts from different specialties."

Table 2 summarizes the studies done in this field over the past 10 years. ${ }^{15-20}$ All these studies were observational and conducted in the United Kingdom or Denmark except for the EPOCH trial which was the largest stepped-wedge cluster randomized trial conducted in 93 NHS hospitals. Surprisingly, EPOCH did not show any mortality benefit after implementation of 37-point EPOCH care pathway. This

Table 2: Studies showing use of multidisciplinary protocol for emergency laparotomy (from 2011 onwards)

\begin{tabular}{|c|c|c|c|c|c|c|c|}
\hline & Year and author & Setting & Type of study & Protocol & Components of protocol & Findings & Remarks \\
\hline 1 & Møller et al. ${ }^{15}$ & $\begin{array}{l}\text { Seven hospitals } \\
\text { in Denmark }\end{array}$ & $\begin{array}{l}\text { Prospective } \\
\text { intervention } \\
\text { group was } \\
\text { compared } \\
\text { with historical } \\
\text { and concur- } \\
\text { rent national } \\
\text { controls (peptic } \\
\text { ulcer perfora- } \\
\text { tion trial) }\end{array}$ & $\begin{array}{l}\text { PULP trial } \\
\text { protocol }\end{array}$ & $\begin{array}{l}\text { - } \text { Evaluation and risk } \\
\text { stratification by senior } \\
\text { - } \text { Avoid surgical delay } \\
\text { - } \text { Timely broad- } \\
\text { spectrum antibiotics } \\
\text { - } \text { Respiratory and } \\
\text { circulatory support } \\
\text { - Antisecretory therapy } \\
\text { - Nutrition and fluids } \\
\text { - } \text { Appropriate analgesia } \\
\text { - Early mobilization }\end{array}$ & $\begin{array}{l}30 \text {-day mortality } \\
\text { rate following } \\
\text { PPU* } 17.1 \% \text { in- } \\
\text { tervention group } \\
27.0 \% \text { control } \\
\text { groups } \\
(p=0.005) .\end{array}$ & $\begin{array}{l}\text { Only peptic } \\
\text { ulcer perfora- } \\
\text { tion patients } \\
\text { were included }\end{array}$ \\
\hline 2 & Huddart et al. ${ }^{16}$ & $\begin{array}{l}\text { Four NHS hospi- } \\
\text { tals of United } \\
\text { Kingdom }\end{array}$ & $\begin{array}{l}\text { Prospective } \\
\text { (before and } \\
\text { after bundle im- } \\
\text { plementation) }\end{array}$ & $\begin{array}{l}\text { ELPQuiC } \\
\text { bundle }\end{array}$ & $\begin{array}{l}\text { Early warning score } \\
\text { and graded escalation } \\
\text { of care (senior clinician } \\
\text { and ICU referral) } \\
\text { - Broad-spectrum } \\
\text { antibiotics for } \\
\text { peritoneal spillage and } \\
\text { or sepsis } \\
\text { - Surgery within } 6 \text { hours } \\
\text { of decision to operate } \\
\text { or next available space } \\
\text { in theater } \\
\text { Goal-directed } \\
\text { resuscitation } \\
\text { ICU admission for } \\
\text { postoperative care }\end{array}$ & $\begin{array}{l}\text { Overall case mix- } \\
\text { adjusted risk of } \\
\text { death decreased } \\
\text { from } 15.6 \text { to } 9.6 \% \\
(p=0.002)\end{array}$ & $\begin{array}{l}\text { Different } \\
\text { process } \\
\text { areas showed } \\
\text { improvement in } \\
\text { all four hospi- } \\
\text { tals to different } \\
\text { degrees reflect- } \\
\text { ing diversity of } \\
\text { care practices }\end{array}$ \\
\hline 3 & $\begin{array}{l}\text { Tengberg } \\
\text { et al. }{ }^{17}\end{array}$ & $\begin{array}{l}\text { Single center of } \\
\text { Denmark }\end{array}$ & $\begin{array}{l}\text { Prospective } \\
\text { (intervention } \\
\text { group was com- } \\
\text { pared with pre- } \\
\text { AHA historical } \\
\text { cohort) }\end{array}$ & $\begin{array}{l}\text { Acute high- } \\
\text { risk abdomi- } \\
\text { nal (AHA) } \\
\text { protocol }\end{array}$ & $\begin{array}{l}\text { - } \quad \text { Educating the staff } \\
\text { - } \quad \text { Eansultant-led care } \\
\text { antibiotics, } \\
\text { - Surgery within } 6 \text { hours } \\
\text { - } \text { Perioperative } \\
\text { hemodynamic } \\
\text { optimization, (stroke } \\
\text { volume guided) } \\
\text { - Intermediate level of } \\
\text { postoperative care } \\
\text { - Standardized pain } \\
\text { management regimen } \\
\text { - Early postoperative } \\
\text { mobilization } \\
\text { - Early enteral feeding }\end{array}$ & $\begin{array}{l}\text { Unadjusted } \\
30 \text {-day mortality } \\
\text { rate was } 21.8 \% \\
\text { control cohort vs } \\
15.5 \% \text { interven- } \\
\text { tion cohort ( } p= \\
0.005 \text { ). }\end{array}$ & $\begin{array}{l}\text { Inclusion } \\
\text { criteria was } \\
\text { emergency } \\
\text { laparotomy } \\
\text { and emergency } \\
\text { laparoscopy }\end{array}$ \\
\hline
\end{tabular}




\begin{tabular}{|c|c|c|c|c|c|c|c|}
\hline & Year and author & Setting & Type of study & Protocol & Components of protocol & Findings & Remarks \\
\hline 4 & $\begin{array}{l}\text { Aggarwal } \\
\text { et al. }{ }^{18}\end{array}$ & $\begin{array}{l}\text { Twenty eight } \\
\text { NHS hospitals } \\
\text { of United King- } \\
\text { dom }\end{array}$ & $\begin{array}{l}\text { Prospec- } \\
\text { tive quality } \\
\text { improvement } \\
\text { study conduct- } \\
\text { ed over } 2 \text { years }\end{array}$ & $\begin{array}{l}\text { Emergency } \\
\text { laparotomy } \\
\text { collaborative } \\
\text { (ELC) }\end{array}$ & $\begin{array}{l}\text { Blood lactate } \\
\text { monitoring } \\
\text { - } \text { Early sepsis } \\
\text { management } \\
\text { - } \text { Transfer to theater } \\
\text { within time goals } \\
\text { - Goal-directed fluid } \\
\text { therapy } \\
\text { - ICU admission } \\
\text { postoperative } \\
\text { - Consultant led } \\
\text { multidisciplinary team }\end{array}$ & $\begin{array}{l}\text { Unadjusted } \\
\text { mortality rate } \\
\text { decreased from } \\
9.8 \% \text { to } 8.3 \% \text { risk- } \\
\text { adjusted mortal- } \\
\text { ity decreased } \\
\text { from } 5.3 \% \text { to } \\
4.5 \%\end{array}$ & $\begin{array}{l}\text { More marked } \\
\text { improvement in } \\
2 \text { nd year of im- } \\
\text { plementation }\end{array}$ \\
\hline 5 & $\begin{array}{l}\text { Burcharth } \\
\text { et al. }{ }^{19}\end{array}$ & $\begin{array}{l}\text { Single center of } \\
\text { Denmark }\end{array}$ & $\begin{array}{l}\text { Observational } \\
\text { study evaluat- } \\
\text { ing bundle im- } \\
\text { plementation } \\
\text { compliance }\end{array}$ & $\begin{array}{l}\text { OMEGA } \\
\text { (optimizing } \\
\text { Emergency } \\
\text { major ab- } \\
\text { dominal } \\
\text { surgery) } \\
\text { treatment } \\
\text { bundle }\end{array}$ & $\begin{array}{l}\text { A detailed standardized } \\
\text { protocol for surgery, emer- } \\
\text { gency, anesthesiology, } \\
\text { radiology, physiotherapy } \\
\text { and nutritional services. }\end{array}$ & $\begin{array}{l}\text { Compliance } \\
\text { of the bundle } \\
\text { implementation } \\
\text { was evaluated } \\
\text { during first year. } \\
\text { The overall com- } \\
\text { pliance rate was } \\
83 \% \text { (min-max } \\
71.4-100 \% \text { ) }\end{array}$ & - \\
\hline 6 & Peden et al. ${ }^{20}$ & $\begin{array}{l}\text { EPOCH trail } 93 \\
\text { NHS hospitals } \\
\text { United King- } \\
\text { dom }\end{array}$ & $\begin{array}{l}\text { Stepped-wedge } \\
\text { cluster rand- } \\
\text { omized trial }\end{array}$ & $\begin{array}{l}\text { EPOCH trail } \\
\text { care path- } \\
\text { way }\end{array}$ & $\begin{array}{l}\text { The pathway had } 37 \\
\text { recommended processes } \\
\text { of care } \\
\text { - } 10 \text { before surgery } \\
\text { - } 16 \text { during surgery } \\
\text { - } 11 \text { after surgery }\end{array}$ & $\begin{array}{l}\text { No Improvement } \\
\text { in survival after } \\
\text { implementation } \\
\text { of Q। }{ }^{\#} \text { program } \\
\text { for patients } \\
\text { undergoing } \\
\text { emergency lapa- } \\
\text { rotomy }\end{array}$ & $\begin{array}{l}\text { Complexity of } \\
\text { an intervention } \\
\text { should be bal- } \\
\text { anced against } \\
\text { its practical } \\
\text { application }\end{array}$ \\
\hline
\end{tabular}

*Perforated peptic ulcer; ${ }^{\#}$ Quality improvement

was in contrast to the findings of all other observational studies which showed mortality benefit after the implementation of care pathways. An insight into the science of quality improvement shows that implementation of complex pathways are difficult to achieve when compared to simple care bundles. Moreover, not all factors can be improved by quality improvement programs, e.g., time to operation theater or CT scan or admission to intensive care unit depends upon the structural aspect of the hospital, i.e., number of operation theaters, CT units, or emergency surgical units available.

European countries like United Kingdom and Denmark have worked exceptionally well in bringing down mortality for emergency abdominal surgeries. Although such national-level integrated quality improvement programs are farfetched ideas in many low- and middle-income countries, but individual hospitals can still work toward quality improvement by local and customized implementation of care bundles or protocols.

\section{Conclusion}

Emergency laparotomies form a heterogeneous group of surgeries with higher mortality when compared to similar elective surgeries. After the introduction of evidence-based pathways and regular audit programs, care for surgical patients has improved in many high-income countries. This is in contrast to low-income and middle-income group of countries, where large number of population lacks access to affordable basic life,saving surgical care. More dedicated efforts and collaboration at international as well as national level are needed to bring quality health care within reach of all inhabitants of the planet.

\section{HighLIGHTS}

- Emergency laparotomies are time-sensitive abdominal surgeries associated with high rate of morality.

- Audits and patient care pathways have been used by many countries to improve the quality of care and reduce mortality.

- Goal-directed resuscitation, consultant-led care, early transfer to operation theater, damage control surgery and resuscitation, postoperative ICU admission, early mobilization, physiotherapy, and dedicated stoma care team are the core strategies to improve outcome in patients undergoing emergency laparotomy.

\section{References}

1. Barazanchi AWH, Xia W, MacFater W, Bhat S, MacFater H, Taneja A, et al. Risk factors for mortality after emergency laparotomy: scoping systematic review. ANZ J Surg 2020. Online ahead of print 10.1111/ ans.16082.

2. Stephens T, Johnston C, Hare S. Quality improvement and emergency laparotomy care: what have we learnt from recent major QI efforts? Clin Med (Lond) 2019;19(6):454-457. DOI: 10.7861/clinmed.2019.0251.

3. https://www.nela.org.uk/downloads/The\%20Fifth\%20Patient $\% 20$ Report\%20of\%20the\%20NELA\%202019\%20-\%20Full\%20Patient\%20 Report.pd.

4. Boyd-Carson H, Gana T, Lockwood S, Murray D, Tierney GM. A review of surgical and peri-operative factors to consider in emergency laparotomy care. Anaesthesia 2020;75(Suppl. 1):e75-e82. DOI: 10.1111/ anae.14821.

5. Martin ND, Patel SP, Chreiman K, Pascual JL, Braslow B, Reilly PM, et al. Emergency laparotomy in the critically ill: futility at the bedside. Crit Care Res Pract 2018;2018:6398917. DOI: 10.1155/2018/6398917. 
6. Ross JT, Matthay MA, Harris HW. Secondary peritonitis: principles of diagnosis and intervention. BMJ 2018;361:k1407. DOI: 10.1136/bmj. k1407.

7. Khan S, Verma AK, Ahmad SM, Ahmad R. Analyzing intra-abdominal pressures and outcomes in patients undergoing emergency laparotomy. J Emerg Trauma Shock 2010;3(4):318-325. DOI: 10.4103/0974-2700.70747.

8. Poulton TE, Moonesinghe R, Raine R, Martin P, National Emergency Laparotomy Audit Project Team. Socioeconomic deprivation and mortality after emergency laparotomy: an observational epidemiological study. Br J Anaesth 2020;124(1):73-83. DOI: 10.1016/j. bja.2019.08.022.

9. Trotter J, Johnston J, Ng A, Gatt M, MacFie J, McNaught C. Is sarcopenia a useful predictor of outcome in patients after emergency laparotomy? A study using the NELA database. Ann R Coll Surg Engl 2018;100(5):377-381. DOI: 10.1308/rcsann.2017.0230.

10. Kim WC, Tesoriero RB, Stein DM. We asked the experts: direct peritoneal resuscitation: a modern adaptation of a historical technique. World J Surg 2020;44(9):2982-2984. DOI: 10.1007/s00268020-05569-0.

11. Richman A, Burlew CC. Lessons from trauma care: abdominal compartment syndrome and damage control laparotomy in the patient with gastrointestinal disease. J Gastrointest Surg 2019;23(2):417-424. DOI: 10.1007/s11605-018-3988-2.

12. Shakerian R, Thomson BN, Gorelik A, Hayes IP, Skandarajah AR. Outcomes in emergency general surgery following the introduction of a consultant-led unit. Br J Surg 2015;102(13):1726-1732. DOI: 10.1002/bjs.9954.

13. Peters AW, Roa L, Rwamasirabo E, Ameh E, Ulisubisya MM, Samad L, et al. National surgical, obstetric, and anesthesia plans supporting the vision of universal health coverage. Glob Health Sci Pract 2020;8(1):1-9. DOI: 10.9745/GHSP-D-19-00314.

14. Mcllveen EC, Wright E, Shaw M, Vella M, Quasim T, Moug SJ. et al. A prospective cohort study characterising patients declined emergency laparotomy: survival in the 'NoLap' population. Anaesthesia 2020;75(1):54-62. DOI: 10.1111/anae.14839.

15. Møller MH, Adamsen S, Thomsen RW, Møller AM. Peptic ulcer perforation (PULP) trial group. Multicentre trial of a perioperative protocol to reduce mortality in patients with peptic ulcer perforation. Br J Surg 2011;98(6):802-810. DOI: 10.1002/bjs.7429.

16. Huddart S, Peden CJ, Swart M, McCormick B, Dickinson M, Mohammed MA, et al. Use of a pathway quality improvement care bundle to reduce mortality after emergency laparotomy. Br J Surg 2015;102(1):57-66. DOI: 10.1002/bjs.9658.

17. Tengberg LT, Bay-Nielsen M, Bisgaard T, Cihoric M, Lauritsen $\mathrm{ML}$, Foss NB, et al. Multidisciplinary perioperative protocol in patients undergoing acute high-risk abdominal surgery. Br J Surg 2017;104(4):463-471. DOI: 10.1002/bjs.10427.

18. Aggarwal G, Peden CJ, Mohammed MA, Pullyblank A, Williams $B$, Stephens T, et al. Evaluation of the collaborative use of an evidence-based care bundle in emergency laparotomy. JAMA Surg 2019;154(5):e190145. DOI: 10.1001/jamasurg.2019.0145.

19. Burcharth J, Abdulhady L, Danker J, Ekeloef S, Jørgensen T, Lauridsen $\mathrm{H}$, et al. Implementation of a multidisciplinary perioperative protocol in major emergency abdominal surgery. Eur J Trauma Emerg Surg 2019. Online ahead of print 10.1007/s00068-019-01238-7.

20. Peden CJ, Stephens T, Martin G, Kahan BC, Thomson A, Everingham K, et al. A national quality improvement programme to improve survival after emergency abdominal surgery: the EPOCH stepped-wedge cluster RCT. Southampton (UK): NIHR Journals Library; 2019. 